\title{
Structural Configuration Systems Analysis for Advanced Aircraft Fuselage Concepts
}

\author{
Vivek Mukhopadhyay, ${ }^{1}$ Jason R. Welstead, ${ }^{2}$ Jesse R. Quinlan ${ }^{3}$ and Mark D. Guynn ${ }^{4}$ \\ NASA Langley Research Center, Hampton, VA 23681
}

\begin{abstract}
Structural configuration analysis of an advanced aircraft fuselage concept is investigated. This concept is characterized by a double-bubble section fuselage with rear mounted engines. Based on lessons learned from structural systems analysis of unconventional aircraft, high-fidelity finite-element models (FEM) are developed for evaluating structural performance of three double-bubble section configurations. Structural sizing and stress analysis are applied for design improvement and weight reduction. Among the three double-bubble configurations, the double-D cross-section fuselage design was found to have a relatively lower structural weight. The structural FEM weights of these three double-bubble fuselage section concepts are also compared with several cylindrical fuselage models. Since these fuselage concepts are different in size, shape and material, the fuselage structural FEM weights are normalized by the corresponding passenger floor area for a relative comparison. This structural systems analysis indicates that an advanced composite double-D section fuselage may have a relative structural weight ratio advantage over a conventional aluminum fuselage. Ten commercial and conceptual aircraft fuselage structural weight estimates, which are empirically derived from the corresponding maximum takeoff gross weight, are also presented and compared with the FEMbased estimates for possible correlation. A conceptual full vehicle FEM model with a double-D fuselage is also developed for preliminary structural analysis and weight estimation.
\end{abstract}

$\begin{array}{lll}g & =\text { acceleration due to gravity. } & \text { Nomenclature } \\ \text { psi } & =\text { pounds per square inch. } \\ P & =\text { cabin internal pressure of } 9.2 \mathrm{psi}(2 P=18.4 \mathrm{psi}) \\ R & =\text { radius of cylindrical fuselage. } \\ t & =\text { plate or shell skin thickness. }\end{array}$

\section{Introduction}

A irframe design to reduce the structural weight of an in-house NASA version of the D8 fuselage concept ${ }^{1-2}$ is Anvestigated in this paper. This D8 concept is characterized by a fuselage with a double-bubble cross-section. Figure 1 shows a set of advanced aircraft fuselage concepts along with a conventional cylindrical fuselage model. A conventional fuselage with stiffened cylindrical section has the structural advantage of containing the cabin-pressure primarily via the outer skin hoop stress or membrane stress PR/t. For a non-cylindrical fuselage, such as a hybridwing-body $^{3-8}$ (HWB) or a double-bubble section fuselage, the cabin design pressure results in significantly higher bending stress on the outer skin. In a properly designed stress-balanced double-bubble section, the membrane stresses from the right and left half can be balanced via the vertical inter-cabin wall. The HWB and double-bubble crosssection fuselage concept with stitched composite construction are presently being studied at NASA. Figure 1 shows a structural configuration development scheme, starting with flat and curved panels and progressing towards structural concepts of advanced fuselage and full aircraft assembly model. The first row shows development of advanced stitched composite panels $^{6}$, also known by the acronym PRSEUS ${ }^{9,10}$ (Pultruded Rod Stitched Efficient Unitized Structure) and the HWB multi-bay test ${ }^{11}$ fuselage built with the PRSEUS technology. The second and third row shows three doublebubble concepts with curved PRSEUS panels, which are analyzed in this paper. A conventional fuselage model that was developed in Ref. 8, is described first as a reference baseline. This is followed by development of three double-

\footnotetext{
${ }^{1}$ Aerospace Engineer, Aeronautics Systems Analysis Branch, MS 442, AIAA Associate Fellow.

2 Aerospace Engineer, NASA ND8 Vehicle Analysis Lead, Aeronautics Systems Analysis Branch, AIAA Member.

${ }^{3}$ Aerospace Engineer, Aeronautics Systems Analysis Branch, AIAA Member.

${ }^{4}$ Aerospace Engineer, AATT Systems Analysis Associate Lead, Aeronautics Systems Analysis Branch, AIAA Senior Member.
} 
bubble fuselage section models for structural analysis ${ }^{12}$ and weight reduction study. A finite element model (FEM) of a notional $125 \%$ scaled up version of the double-bubble D8 aircraft concept is also developed for preliminary structural analysis and weight estimation. All these different fuselage and vehicle models are compared in terms of structural deflection, stress, strain and structural weight. For a relative efficiency comparison of these different fuselage concepts, each fuselage FEM weight is normalized by the corresponding passenger floor area, which is a measure of payload capacity or revenue capability.

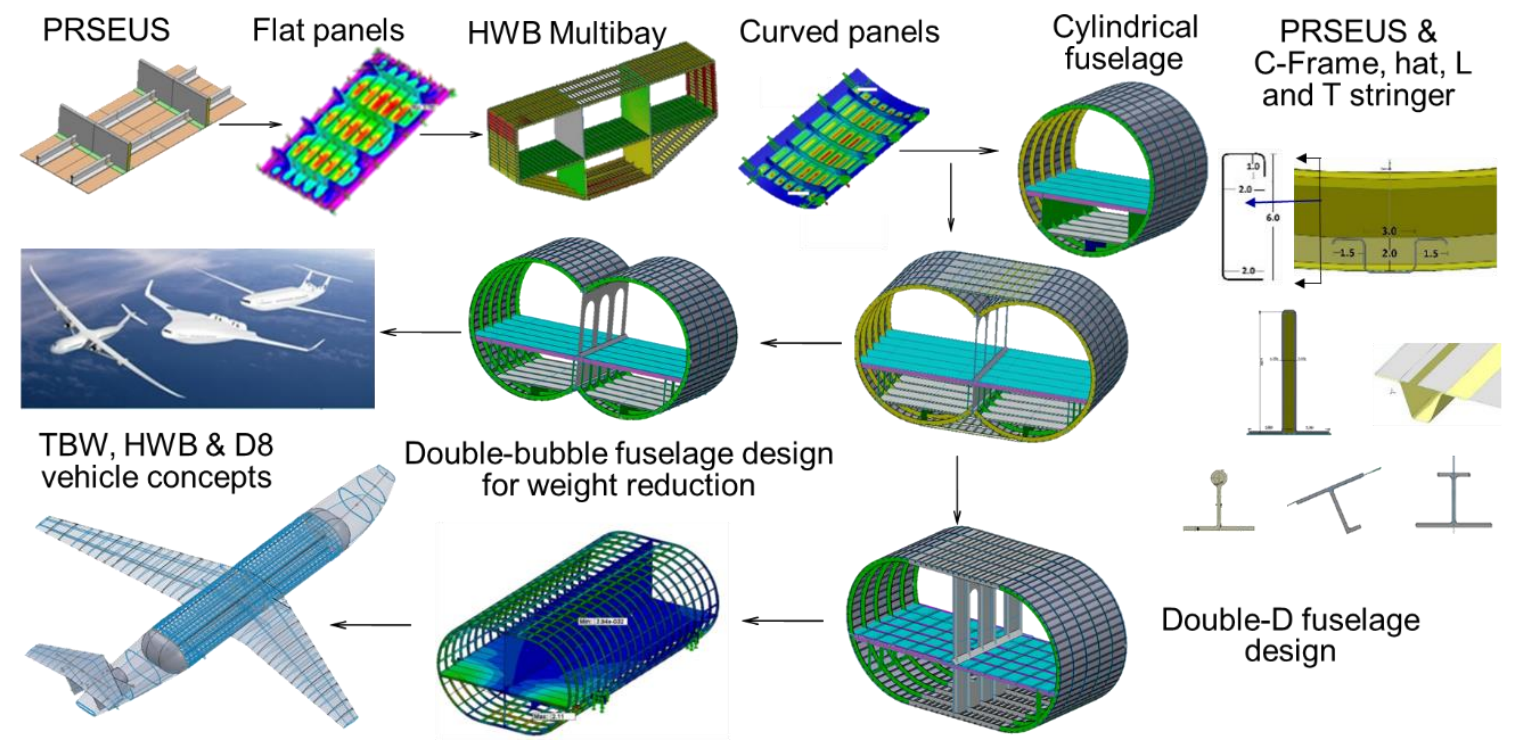

Figure 1. Efficient structural configuration development scheme for advanced aircraft concepts.

\section{Cylindrical Section Fuselage}

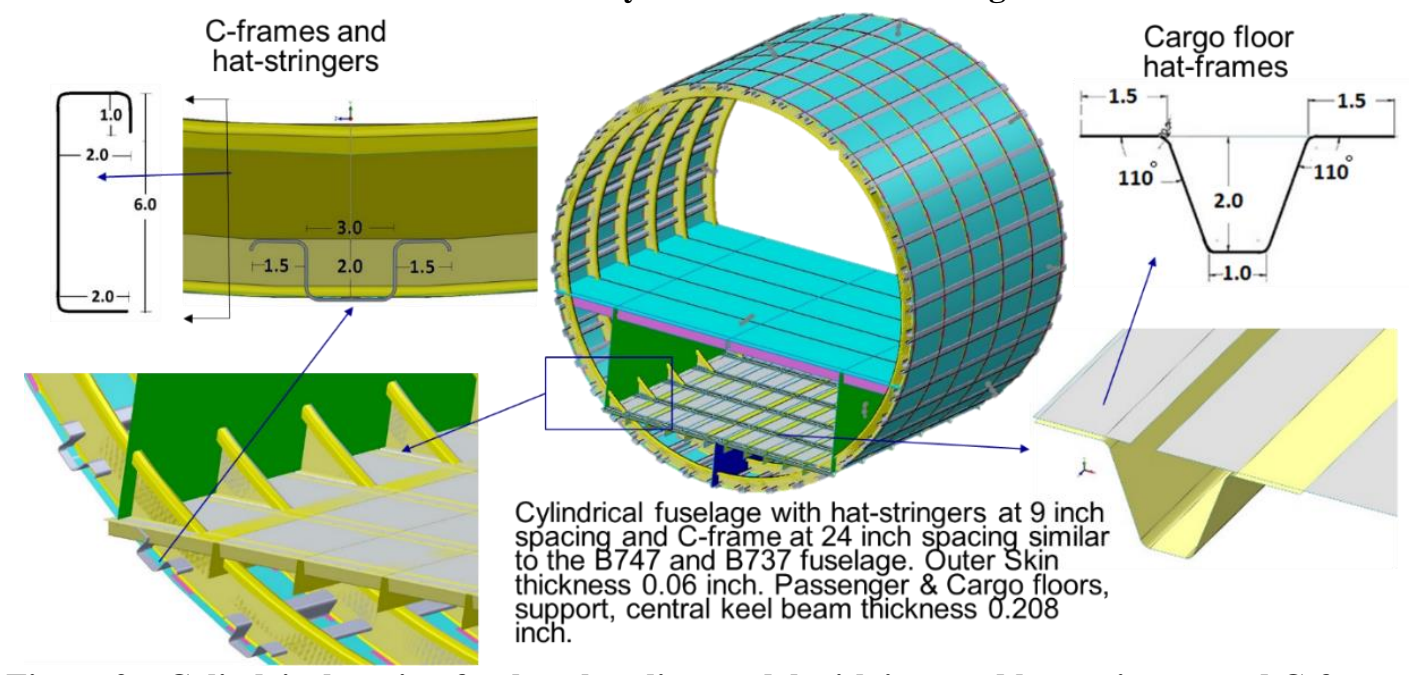

Figure 2a. Cylindrical section fuselage baseline model with inverted hat-stringers and C-frames.

Figure 2a shows a preliminary FEM model of a conventional aircraft fuselage assembly ${ }^{8}$ similar to the Boeing Company 737 and 747 aircraft contruction with frame-stiffened curved panels, and inverted hat-stringers. The model also includes passenger and cargo floors with supports and a central keel beam. This baseline 180-inch diameter fuselage section is stiffened with six circular C-section frames at $24 \mathrm{inch}$ spacing. The outer skin is also stiffened with 60 axial hat-stringers at 9.4 inch radial spacings. The passenger floor is stiffened with seven L-section cross-frames and a central floor-beam and two vertical floor-supports. The cargo floor is stiffened with hat stiffeners, L-frames and a vertical keel beam at the center. The right and left end of the passenger and cargo floors are assumed fixed for the FEM analysis in all cases. Figure $2 b$ shows the corresponding deflection and von Mises stress distribution of this 
aluminum cylindrical fuselage section with $18.4 \mathrm{psi}$ cabin design pressure, a distributed passenger load of $1 \mathrm{psi}$ and a cargo load of 2 psi. The maximum deflection is 0.44 inch on the flat passenger floor. The maximum von Mises stress is 46,000 psi near the keel beam-skin junction, and the minimum factor of safety is 1.5 at that area. The stresses on the outer skin and frames are well within the allowable 73,000 psi yield stress of the aluminum alloy. Note that with this $90 \mathrm{inch}$ radius aluminum fuselage and the outer skin thickness of $0.06 \mathrm{inch}$, the ideal hoop stress $P R / t=27,600$ psi. From the FEM analysis, the outer skin stresses range between 27,000 and 38,000 psi. The assumed shell thicknesses are generally adequate for this preliminary structural design with aluminum alloy. However for stitchedcomposite material, higher skin thicknesses are required.

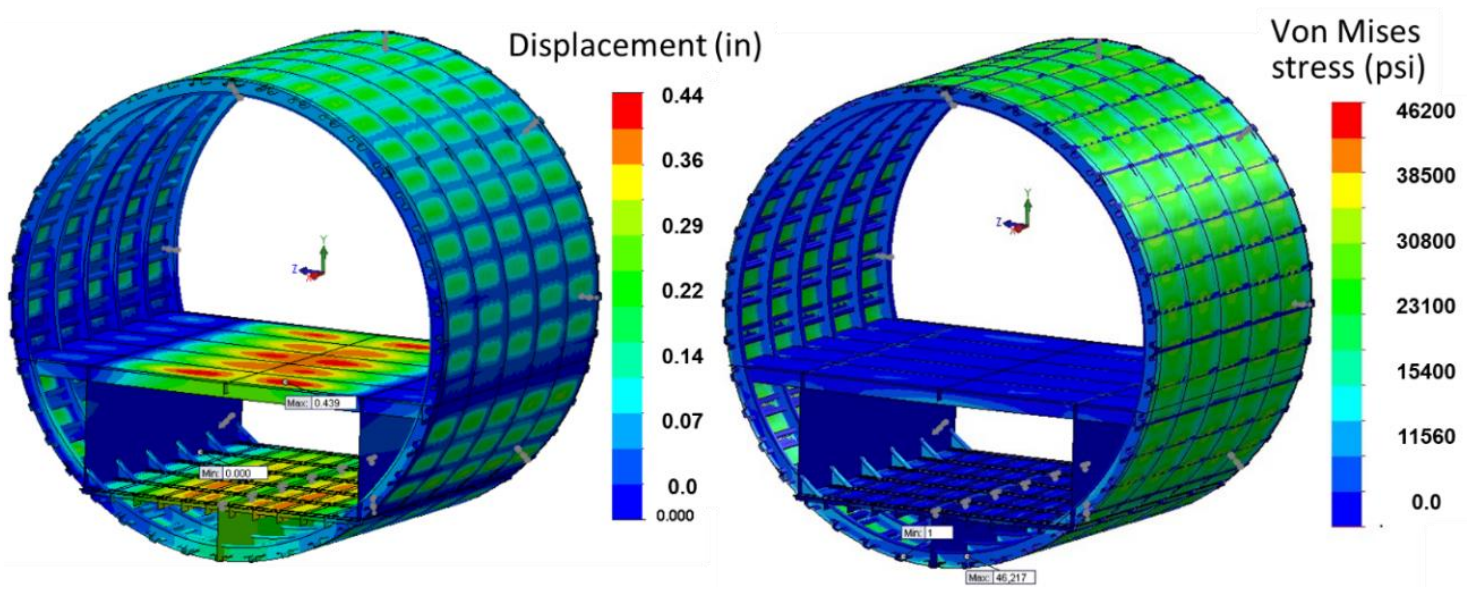

Figure 2b. Cylindrical section fuselage displacement and stress distribution with 18.4 psi cabin pressure.

\section{Double-Bubble Section Fuselage}

The first MIT D8 full vehicle configuration design with double-bubble-section fuselage was presented in Refs. 1 and 2. In this paper, only the fuselage section structural design is considered. Three structural cross-section architectures of the double-bubble fuselage section concepts are shown in Fig. 3. All three section concepts have an inter-cabin wall, which transfers and balances the membrane-stress due to internal cabin design pressure, in addition to the curved foam-core frames and longitudinal L-stringers, which stiffen the outer shell. In both the concept (a) and (b), the right and left $\mathrm{C}$ shaped segments are joined to the inter-cabin wall at an angle of 120 degrees to balance the $P R / t$ hoop stress. ${ }^{8}$ The first concept (a) has aerodynamic fairing panels at the crown and keel. In concept (b), these fairings are eliminated to reduce weight. But this will have aerodynamic flow issues, which may affect its performance. The race-track concept (c) is not hoop-stress-balanced, but it eliminates the extra weight of the fairing and the walljoint complexity. The inter-cabin walls still reduce the higher bending stresses at the flat crown surface and the cargokeel surface. The extra cargo-floor weights in concept (a) and (b) are also eliminated in concept (c). In addition, the available cargo volume and floor space are also increased.

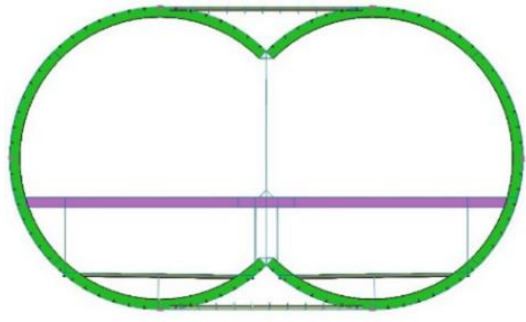

(a)

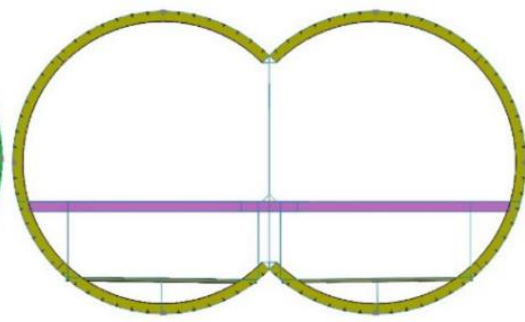

(b)

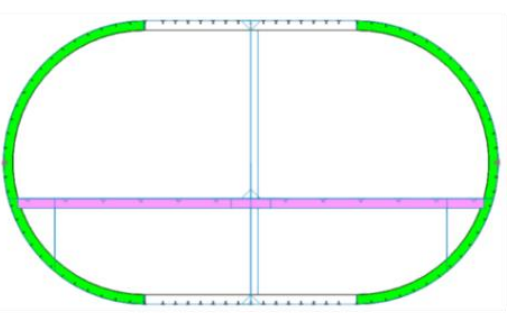

(c)

Figure 3. Three double-bubble fuselage section architecture for FEM model development: (a) double-bubble section with the crown and keel aerodynamic fairing; (b) double-bubble section without the two aerodynamic fairings; and (c) race-track shaped double-D section with reinforced pressure bearing crown and keel floors and inter-cabin wall.

Figure 4a shows the structural component model of the first double-bubble section structure concept from Fig. 3(a). An older version of this concept was analyzed in Ref. 8. In this newer concept, cutouts were introduced on the 
vertical supports of the passenger floor and on the inter-cabin walls. Support walls connecting the crown and keel fairing panels to the inter-cabin wall were eliminated. Advanced stitched composite PRSEUS construction with foamcore frame ${ }^{8}$ was used for the four inner frames. The two outer frames have solid composite core to allow bolt attachment to the adjacent fuselage sections. The pultruded rod-stringers in the previous PRSEUS version ${ }^{8}$ were replaced by L-stringers. Due to the introduction of cutouts on the inter-cabin wall, composite material was replaced aluminum alloy to reduce tensile stress.
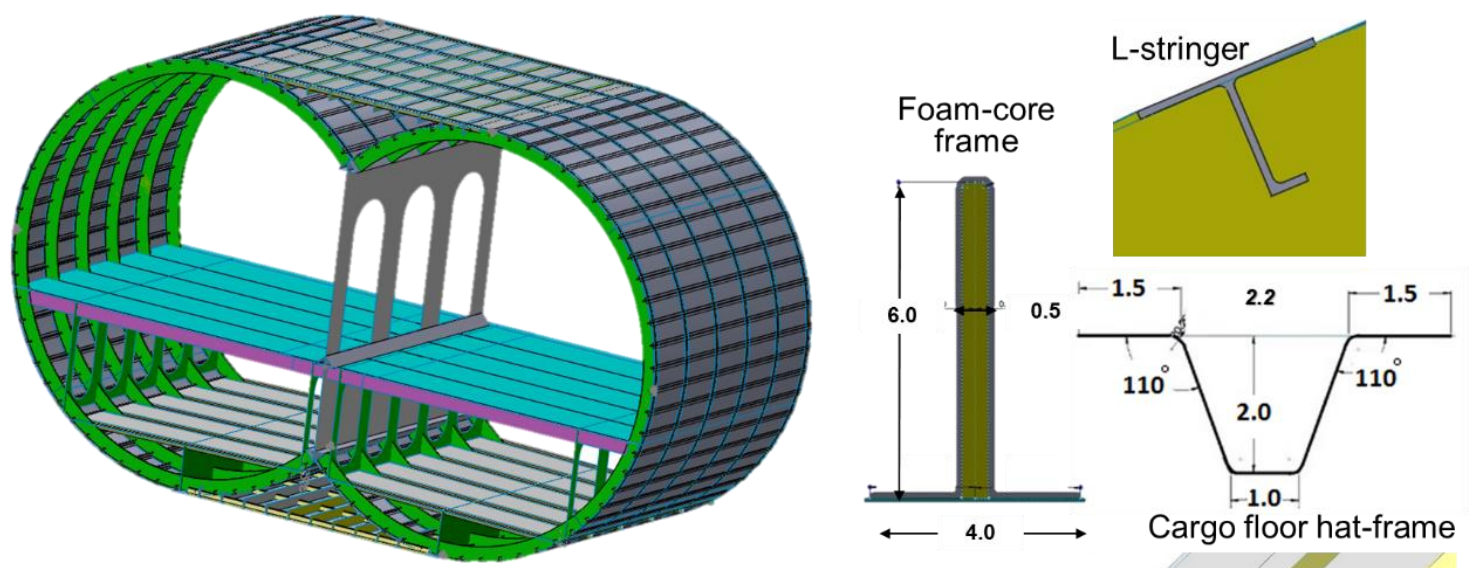

PRSEUS double-bubble fuselage: 180 inch high, 270 inch wide, frames at 24 inch spacing; L-stringers at 9.4 inch spacing; skin thickness 0.104 inch; floor, keel beam, corner joints, cabin-wall thickness 0.208 inch; loads 18.4 psi cabin pressure, 1 psi on passenger floor, 2 psi on cargo floor and $0.1 \mathrm{psi}$ on the crown and keel fairing panels.

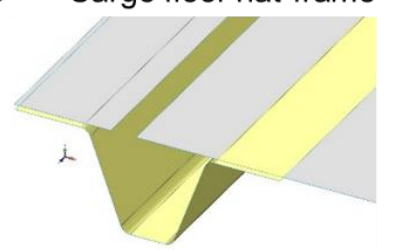

Figure 4a. Double-bubble fuselage section contruction with foam-core frame and L-stringers.
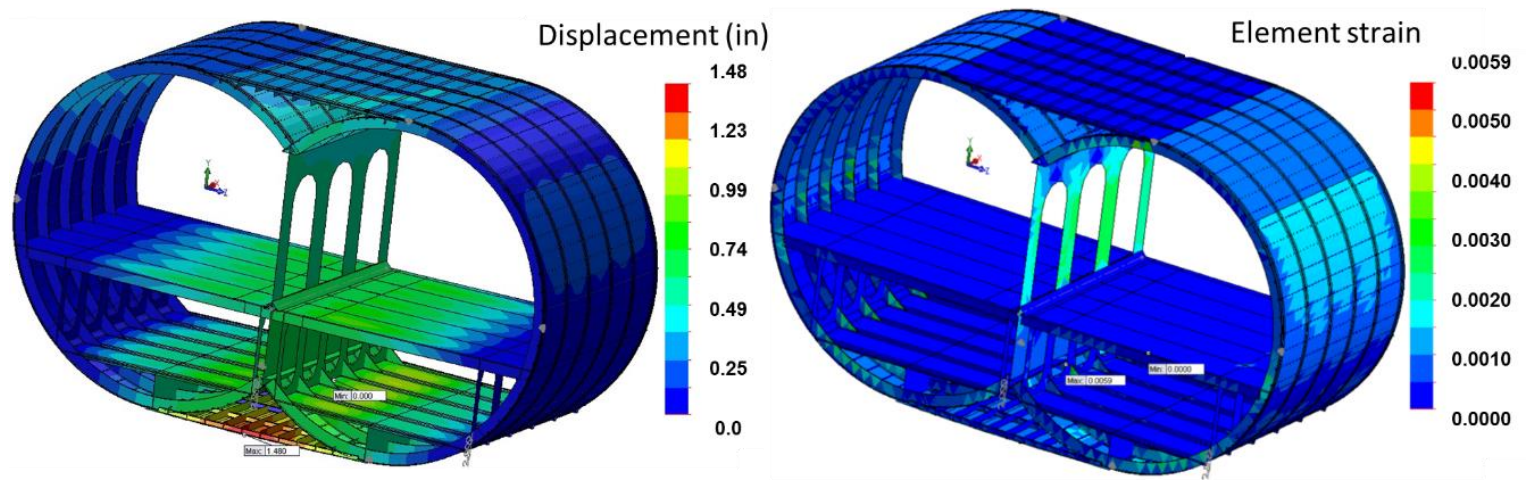

Figure 4b. Double-bubble fuselage section displacement and element strain with 18.4 psi cabin pressure.

The structural displacement and the element strain distribution with the 18.4 psi cabin design pressure are shown in Fig. 4b. The passenger floor load of 1 psi and a cargo floor load of 2 psi were also applied. A representative lift pressure load of $0.1 \mathrm{psi}$ is applied to the upper and lower fairings. The maximum deflection is 1.48 inch on the fairing walls. The maximum average element strain is 0.0059 at the cargo-floor, frame and cabin-wall junction. The maximum Von Mises stresses are generally within the allowable design limit of 46,000 psi except at the mid-cabin floor support junction with the cargo floor edge attachments where the local nodal von-mises stress is $74,000 \mathrm{psi}$. At these junctions and attachment points, the minimum factor of safety falls locally below 1 to 0.63 . These complex junctions and shell free edges need additional splicing and doublers to satify the factor of safety constraint. But this may not affect the overall weight significantly.

Table 1 shows a summary of the component weight along with a pie chart to show the percentage of total weight contributed by each of the five groups. The total FEM structural weight is $3752 \mathrm{lb}$. The ratio of FEM structural weight over passenger floor area is $14.43 \mathrm{lb} / \mathrm{ft}^{2}$ when divided by the passenger floor area of $260 \mathrm{ft}^{2}$. 
Table 1. Component weight of PRSEUS double-bubble fuselage section.
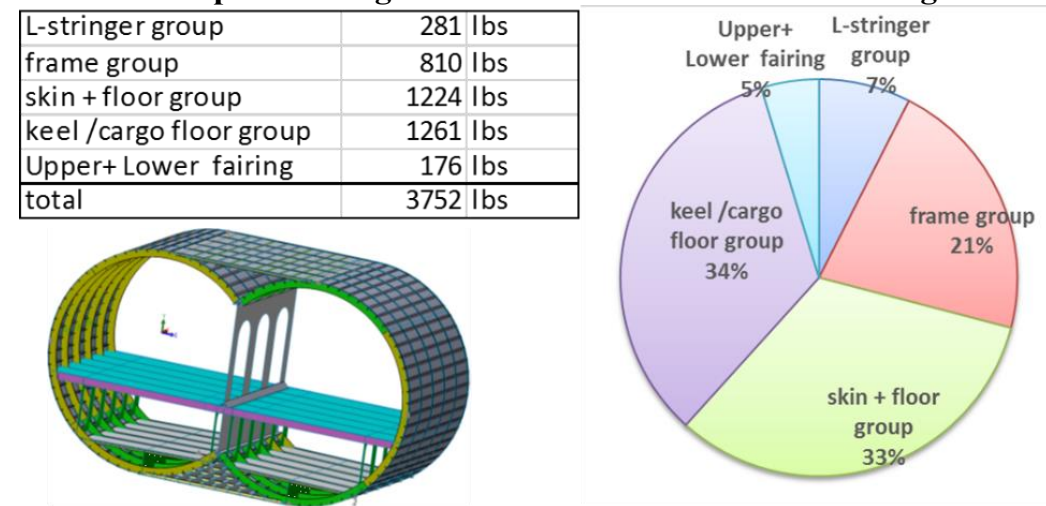

IV. Double-C Section Fuselage

In order to investigate additional reduction in structural weight, the cross-section concept in Fig. 3(b) is considered next. In this concept, the top and bottom aerodynamic fairings were eliminated. The inter-cabin wall cutouts and floor support cutouts were retained as shown in Fig. 5a. The structural displacement analysis, and element strain with 18.4 psi cabin design over-pressure are shown in Fig. 5b. With the 18.4 psi cabin over-pressure and cargo floor load of $2 \mathrm{psi}$, the maximum deflection is about $1.52 \mathrm{inch}$ on the cargo floors, which is slightly higher than the concept shown in Fig. 4a. The element strain distribution shows that the averaged element maximum strain is highest at the cargo-floor junction with the cabin wall and outer framed skin. The stresses are within allowable limits of the stitched composite material except at the floor-support and cargo-floor junction, where the local minimum factor of safety is 0.86 . As stated before, these local design issues will be addressed in the future. In addition to these joint stress issues, this double-C configuration may have unusual aerodynamic flow in the mid-fuselage channel.
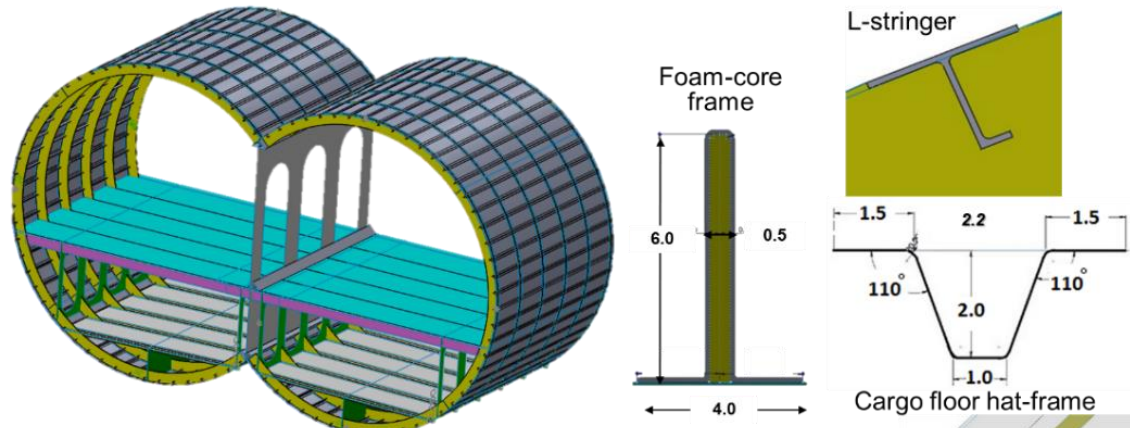

Modified double-bubble fuselage without crown and keel fairing panels: 180 inch high, 270 inch wide; frames at 24 inch spacing; L-stringers at 9.4 inch spacing; skin thickness 0.104 inch; floor, keel beam, corner joints, cabin wall thickness 0.208 inch, Aluminum inter-cabin wall with cutouts; loads:- 18.4 psi cabin pressure, $1 \mathrm{psi}$ on passenger floor, and $2 \mathrm{psi}$ on cargo floor.

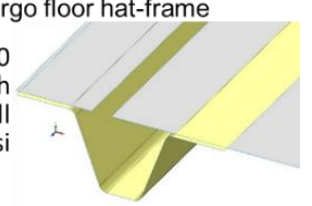

Figure 5a. Modified stress-balanced double-bubble fuselage section configuration with composite foam core frame and stitched composite skin.
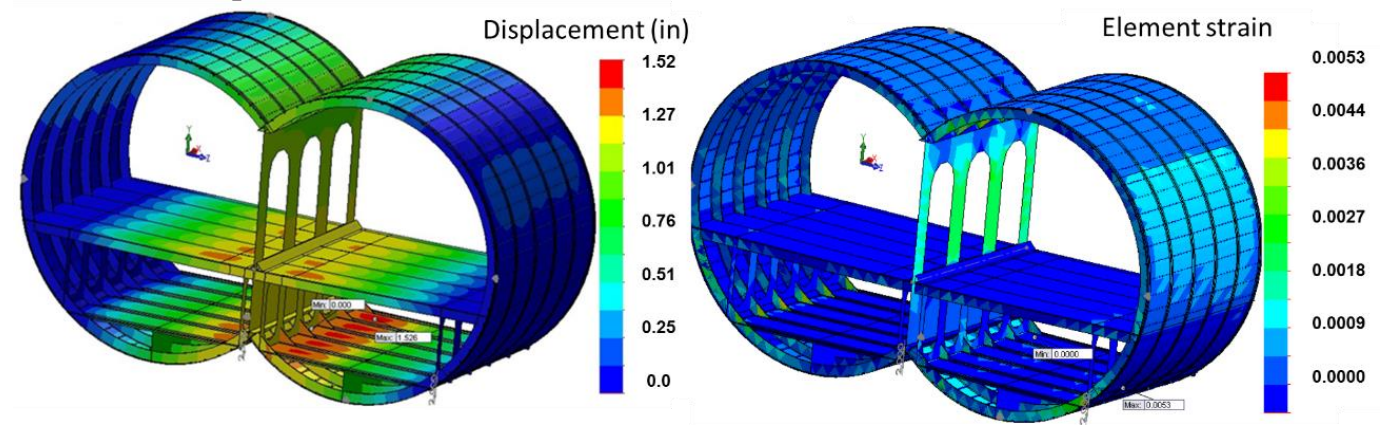

Figure 5b. Displacement and element strain distribution with 18.4 psi cabin internal pressure. 
Table 2. Component weight of modified double-bubble fuselage section.

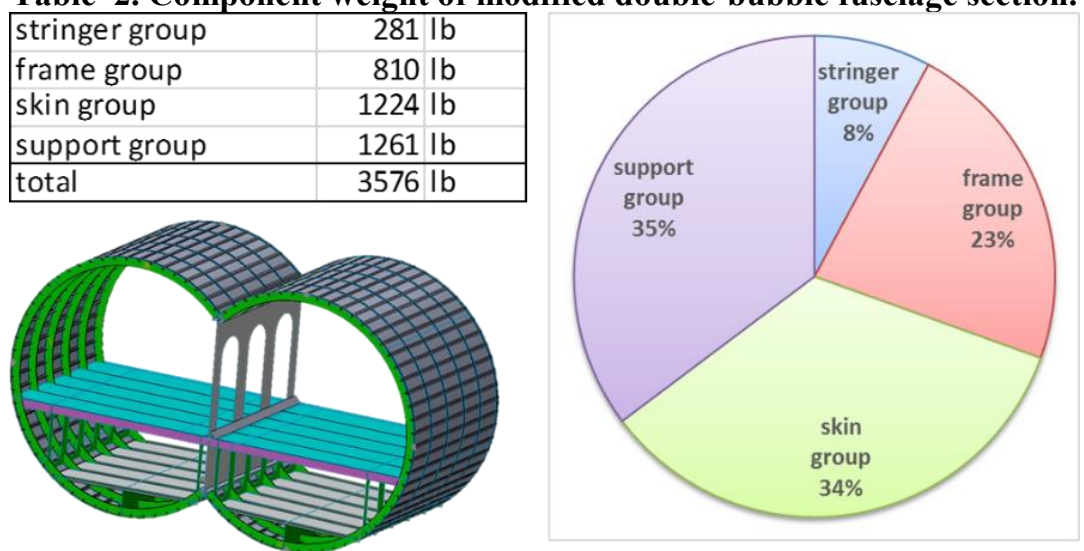

The structural component group weight of the modified double-bubble fuselage section is presented in Table 2 , along with a pie chart to show the percentage of total weight contributed by each of the four groups. Without the upper and lower fairings, the total fuselage weight is reduced to $3576 \mathrm{lbs}$. The ratio of FEM structural weight over passenger floor area is now $13.75 \mathrm{lb} / \mathrm{ft}^{2}$ with the passenger floor area of $260 \mathrm{ft}^{2}$.

\section{Double-D Section Fuselage}

The third structural section concept shown in Fig. 3(c) may be a possible alternative to alleviate both the structural and aerodynamic issues. The finite element model description of this concept is shown in Fig. 6a. The structural displacement and element strain distribution with 18.4 psi cabin design over-pressure, 1 psi passenger-floor load and 2 psi cargo floor load are shown in Fig.6b. The maximum deflection is 1.66 inch on the passenger floor. The maximum element strain is 0.009 at the mid-cabin wall and crown junction, which is above the allowable limit of 0.007 for the stitched composite material. The von Mises stress distribution is generally within the allowable yield stress of 46,000 psi except at an area near the mid-cabin wall and crown junction where the maximum von Mises stress is 59,000 psi and the local minimum factor of safety is 0.78 . As expected, these critical areas have significantly higher bending stresses, and will need local structural braces and doublers to bring the local factor of safety to above 1 . These design issues will be addressed in future with improved modeing and data analysis.

The structural component group weight is presented in Table 3, along with a pie chart to show the percentage of total weight contributed by each of the four groups. The total fuselage structural weight is computed at $3418 \mathrm{lb}$. The ratio of FEM structural weight over passenger floor area of $260 \mathrm{ft}^{2}$ is $13.15 \mathrm{lb} / \mathrm{ft}^{2}$, which is lower than those for the double-bubble concepts shown in Fig. 3(a) and (b).
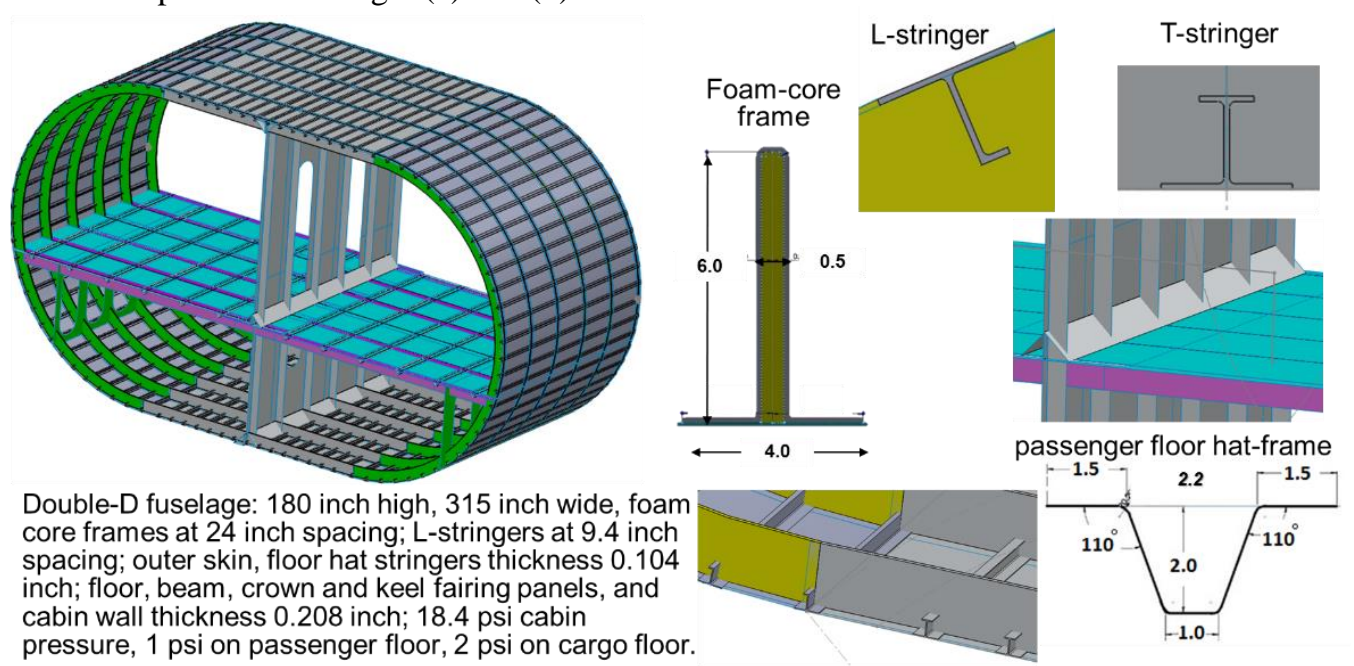

Double-D fuselage: 180 inch high, 315 inch wide, foam core frames at 24 inch spacing; L-stringers at 9.4 inch spacing; outer skin, floor hat stringers thickness 0.104 inch; floor, beam, crown and keel fairing panels, and cabin wall thickness 0.208 inch; 18.4 psi cabin pressure, 1 psi on passenger floor, 2 psi on cargo floor.

Figure 6a. Race-track shaped Double-D fuselage section FEM model Configuration. 

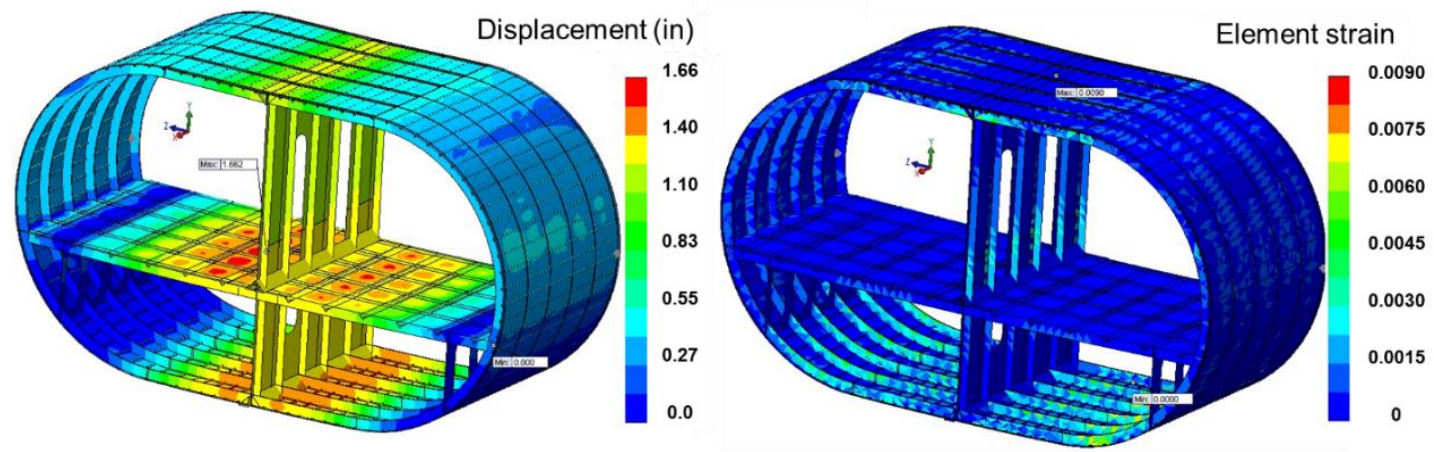

Figure 6b. Displacement and element strain distribution with 18.4 psi cabin over-pressure.

Table 3. The race-track shaped Double-D fuselage section component weight.
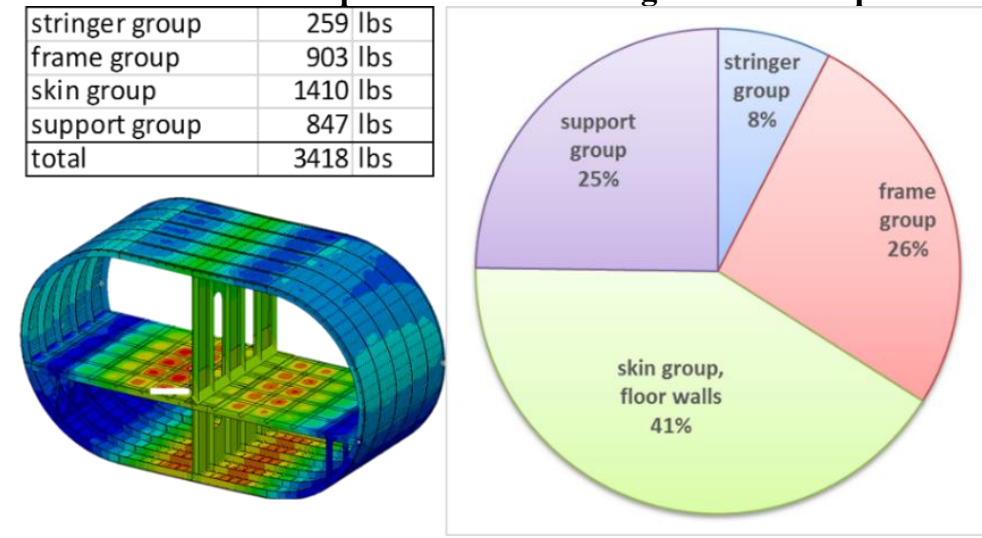

Table 4 shows a comparison of structural FEM weights of eight different fuselage section concepts, some of which were presented in Ref. 8. These eight concepts are as follows: 1. Advanced stitched composite (PRSEUS) Hybrid Wing Body ${ }^{8}$ Multi-bay section and foam-core frame; 2 . Cylindrical fuselage ${ }^{8}$ section with stitched composite (PRSEUS); 3. Cylindrical fuselage section with foam-core composite frame and hat-stringers; 4. Cylindrical fuselage section with inverted hat-stringers and C-Frames; 5 . Conventional aluminum cylindrical fuselage section with inverted hat-stringers and C-Frames ${ }^{8} ; 6$. Modified double-bubble section fuselage with inter-cabin wall cutouts; 7. Modified double-bubble fuselage section without the crown and keel fairing; and 8. Double-D race-track shaped section fuselage concept with reinforced inter-cabin wall and cargo floor.

Table 4. Comparison of the ratio of fuselage section FEM structural weight over passenger floor area for the three double-bubble fuselage section concepts and several previous conceptual designs from Ref. 8.

\begin{tabular}{|c|c|c|c|c|c|c|c|c|}
\hline $\begin{array}{l}\text { Fuselage section } \\
\text { Concept }\end{array}$ & $\begin{array}{l}\text { 1. HWB } \\
\text { multibay rod- } \\
\text { stringer SW } \\
\text { frame }\end{array}$ & $\begin{array}{l}\text { 2. Cyl } \\
\text { fuselage } \\
\text { CFrameA } \\
\text { PRSEUS }\end{array}$ & $\begin{array}{l}\text { 3. Cyl-sec } \\
\text { fuselage } \\
\text { Hat-stringer }\end{array}$ & $\begin{array}{l}\text { 4. Cyl-sec fus } \\
\text { Inv-Hat } \\
\text { stringer C- } \\
\text { Frame }\end{array}$ & $\begin{array}{l}\text { 5. AL Cyl-Fus inv- } \\
\text { hat stringer C- } \\
\text { Frame }\end{array}$ & $\begin{array}{l}\text { 6. Double } \\
\text { bubble w } \\
\text { cutouts }\end{array}$ & $\begin{array}{l}\text { 7. Double- } \\
\text { bubble w/o } \\
\text { fairing }\end{array}$ & $\begin{array}{l}\text { 8. Double D } \\
\text { race-track }\end{array}$ \\
\hline Part assembly name & $\begin{array}{l}\text { HWB } \\
\text { MultiBAY6 }\end{array}$ & CFrameA & CFrame $3 \mathrm{C}$ & CFrameConv[5] & CFrameConv[6] & \begin{tabular}{|l|} 
CFrame \\
Fuselage $8 \mathrm{DB}[4]$
\end{tabular} & $\begin{array}{l}\text { CFrame } \\
\text { Fuselage8DB[5] }\end{array}$ & CFrame4DB \\
\hline $\begin{array}{l}\text { Construction \& } \\
\text { Material }\end{array}$ & \begin{tabular}{|l} 
PRSEUS \\
advanced
\end{tabular} & \begin{tabular}{|l} 
PRSEUS \\
advanced
\end{tabular} & C-Frame & $\begin{array}{l}\text { C- Frame + hat } \\
\text { stringers }\end{array}$ & all ALUMINUM & $\begin{array}{l}\text { Composite, L- } \\
\text { stringer }\end{array}$ & $\begin{array}{l}\text { Composite, L- } \\
\text { stringer }\end{array}$ & $\begin{array}{l}\text { Composite,L, } \\
\text { T stringer }\end{array}$ \\
\hline fuselage length $\mathrm{ft}$ & 6.7 & \begin{tabular}{|l|}
10.3 \\
\end{tabular} & 10.3 & \begin{tabular}{|r|}
10.3 \\
\end{tabular} & 10.3 & \begin{tabular}{|r|}
10.3 \\
\end{tabular} & 10.3 & 10.3 \\
\hline fuselage width & 30.0 & 14.4 & 14.4 & 14.4 & 14.4 & 25.2 & 25.2 & 25.2 \\
\hline passenger area $\mathrm{ft}^{\wedge} 2$ & 200 & 149 & 149 & 149 & 149 & 260 & 260 & 260 \\
\hline fuselage weight, lbs & 2320 & 1900 & 1882 & 1789 & 2195 & 3752 & 3576 & 3418 \\
\hline $\begin{array}{l}\text { fuselage FEM wt } \\
\text { /passenger floor area }\end{array}$ & 11.60 & 12.76 & 12.63 & 12.01 & 14.73 & 14.43 & 13.75 & 13.15 \\
\hline
\end{tabular}


Because these eight fuselage section concepts are different in shape, size, material and construction, each FEM weight is normalized by the corresponding passenger floor area for a meaningful comparison. The fuselage floor area could be a measure of payload capacity or revenue generating capability. The ratio of FEM weight ratio over passenger floor area is shown in the last row of Table 4. This FEM weight ratio varies from $11.6 \mathrm{lb} / \mathrm{ft}^{2}$ for the advanced composite Hybrid Wing Body (HWB) multi-bay section ${ }^{8}$ (without bulkhead), to $14.73 \mathrm{lb} / \mathrm{ft}^{2}$ for the conventional aluminum cylindrical section fuselage with inverted hat-stringers and C-Frames.

The modified double-bubble section in Fig 3 a was derived from a previous design ${ }^{8}$ with advanced composite material. The modifications included cutouts on the inter-cabin wall and floor supports in order to reduce the weight. However it resulted in higher stress on the inter-cabin wall. Hence, aluminum alloy was used instead for the intercabin wall, and floor supports. The ratio of the FEM weight to the passenger floor area was computed to be 14.43 $l b / f t^{2}$ (concept 6 in Table 4). In the next modified double-bubble section shown in Fig 3b, the crown and keel fairing panels are excluded. Hence, this weight ratio is reduced to $13.75 \mathrm{lb} / \mathrm{ft}^{2}$ (concept 7 in Table 4). In the double-D racetrack section design with reinforced inter-cabin wall, crown and keel floor (Fig. 3c), the FEM weight ratio is reduced further to $13.15 \mathrm{lb} / \mathrm{ft}^{2}$. The redesigned race-track shaped double-D fuselage exhibits relatively lower structural weight in comparison to the double-bubble concepts in Fig. 3a and b.

The bar chart in Fig. 7 shows the ratio of fuselage section FEM weight to the corresponding passenger floor area (from Table 4, last row) of these eight different concepts, which are ordered from lowest to the highest. Although these eight fuselage section concepts are quite different in construction, shape and size, an important measure of the structural efficiency can be visualized in Fig. 7.

FUSELAGE SECTION WEIGHT/PASSENGER AREA (LB/FT^2)

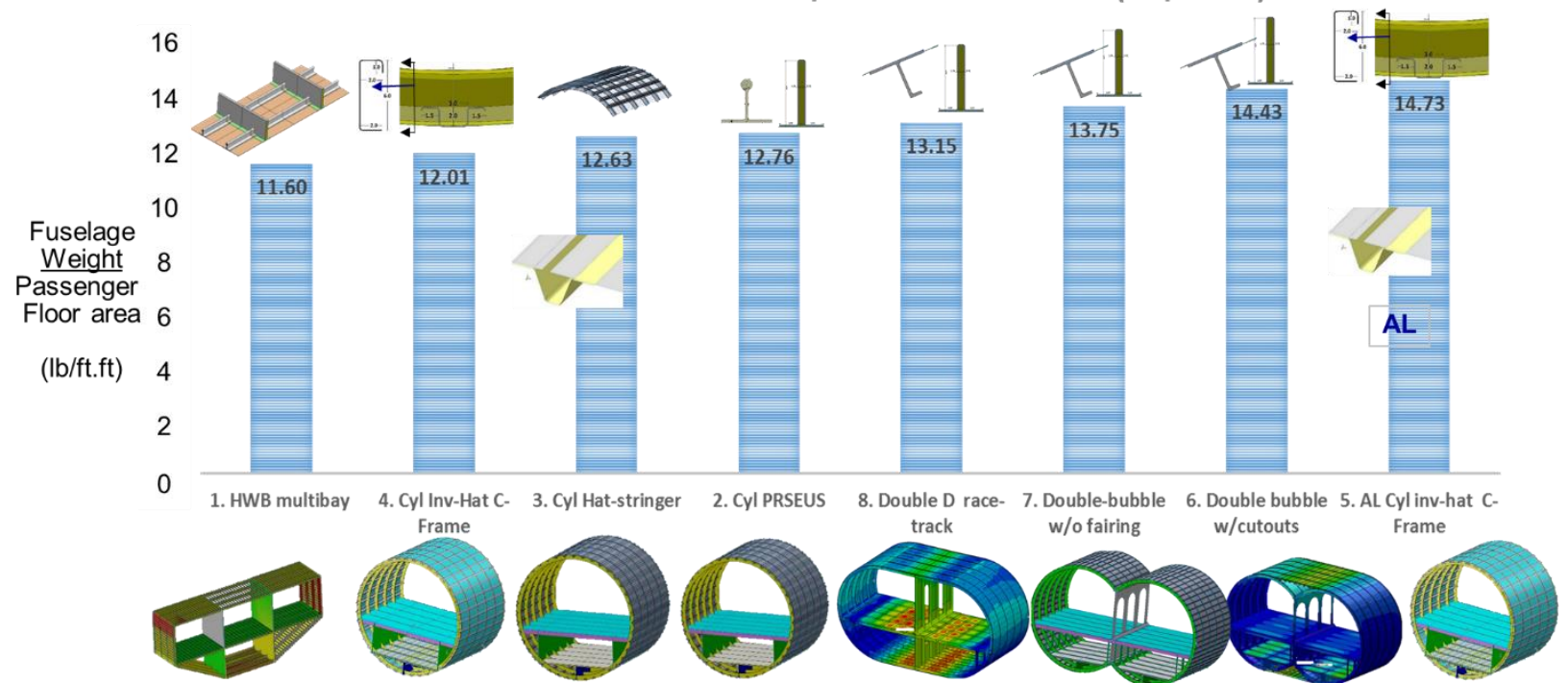

Figure 7. Bar chart comparison of the ratio of eight fuselage section FEM structural weight/passenger floor area $\left(\mathbf{l b} / \mathrm{ft}^{2}\right)$, in ascending order.

\section{Full Vehicle Fuselage Weight Analysis}

Structural weight analysis of several widely different conceptual fuselage section were described in the previous sections with only one critical design static cabin-pressure load condition. Other load conditions also are very important for the fuselage structural design and resulting weight. In addition, fuselage structural weight has many components such as landing gear support, cargo handling equipment, fuel tank, wing carry-through structure, nose and tail cone, bulkheads, door and window reinforcements, etc. Hence, it would be informative to compute and compare the ratio of total fuselage structural weight over the passenger floor area for existing commercial transport aircraft and some advanced conceptual aircraft designs. Table 5 shows one such comparison for 10 different aircrafts, namely; 1. Boeing 777-200 ER; 2. Boeing 747-400 ER; 3. Airbus A380-300; 4. Boeing 765-093 concept; 5. Boeing BWB800 concept; 6 . Boeing BWB400 ${ }^{10,11}$ concept; 7. NASA OREIO ${ }^{4}$ concept; 8 . Boeing OREIO ${ }^{3}$ concept; 9 . Boeing 737-300; and 10. D8 ${ }^{1,2}$ double-bubble concept. The last two rows show the corresponding full vehicle structural weight and the fuselage structural weight, each normalized by the passenger floor area. 
The total structural weight and the fuselage weight are computed from the maximum takeoff gross weight (MTOGW), vehicle dimensions and an regression-based empirical weight estimation method presented in the aircraft conceptual design text book by Raymer ${ }^{13}$ and design weight data presented in NASA contractor ${ }^{3,10,11}$ reports. The passenger floor area is computed by multiplying fuselage length and width for a single deck aircraft. Only for the Airbus 380, the fuselage projected area is multiplied by 1.6 to account for the two deck passenger configuration. The ratio of the total fuselage empirical weight over the corresponding passenger floor area is plotted as a bar chart in ascending order in Fig. 8. The regression-based empirical method ${ }^{13}$ generally applies only to conventional commercial transport aircraft. Hence, the full vehicle fuselage weight estimation method do not strictly apply to non-conventional aircrafts such as the D8, OREIO and BWB concepts. However, the trend in the fuselage structural weight per unit floor area shown in Fig. 8 (from Table 5) is quite interesting. For the cylindrical aluminum fuselage section, shown in Fig. 3, the ratio of structural FEM weight over passenger floor area is $14.73 \mathrm{lb} / \mathrm{ft}^{2}$. The ratio of the entire fuselage structural weight over total passenger floor area for the conventional 777-ER transport aircraft (Fig. 8) is $14.85 \mathrm{lb} / \mathrm{ft}^{2}$. Although these were estimated by entirely different methods, the normalized weight ratios are relatively close and complement each other.

Table 5. Comparison of existing and concept aircraft fuselage empirical weight based on the vehicle maximum takeoff gross weight.

\begin{tabular}{|c|c|c|c|c|c|c|c|c|c|c|c|}
\hline ITEMS & unit & $\begin{array}{l}\text { 1. Boeing } \\
\text { 777-ER }\end{array}$ & $\begin{array}{l}\text { 2. Boeing } \\
747-400 \mathrm{ER}\end{array}$ & $\begin{array}{l}\text { 3. Airbus } \\
\text { A380-800 }\end{array}$ & $\begin{array}{l}\text { 4. Boeing } \\
765-093 \\
\text { NASA NRA }\end{array}$ & $\begin{array}{l}\text { 5. BWB800 } \\
\text { Boeing } \\
\text { NASA NRA }\end{array}$ & $\begin{array}{l}\text { 6. BWB400 } \\
\text { Boeing } \\
\text { NASA NRA }\end{array}$ & $\begin{array}{l}\text { 7. OREIO } \\
\text { NASA NRA }\end{array}$ & $\begin{array}{l}\text { 8. OREIO } \\
\text { Boeing } \\
\text { Report }\end{array}$ & $\begin{array}{l}\text { 9. Boeing } \\
737-300\end{array}$ & $\begin{array}{l}\text { 10. ND8 } \\
\text { DB }\end{array}$ \\
\hline MTOGW & $\mathrm{Ib}$ & 614428 & 655654 & 948778 & 173871 & 806852 & 404372 & 453886 & 479529 & 138500 & 160000 \\
\hline fuselage length & $\mathrm{ft}$ & 209 & 231 & 239 & 124.75 & 140 & 100 & 103 & 103 & 102 & 102 \\
\hline fuselage width & $\mathrm{ft}$ & 20 & 20 & 23 & 17 & 70 & 40 & 57 & 57 & 12 & 17 \\
\hline passenger area & $\mathrm{ft}^{\wedge} 2$ & 4180 & 4620 & 8795 & 2079 & 7697 & 3142 & 4650 & 4650 & 1224 & 1734 \\
\hline total structure weight & $\mathrm{Ib}$ & 167832 & 180841 & 284731 & 49741 & 266288 & 121587 & 134659 & 140281 & 27419 & 39024 \\
\hline fuselage weight & $\mathrm{Ib}$ & 62064 & 67816 & 97034 & 21444 & 77005 & 38370 & 45381 & 51600 & 16053 & 17432 \\
\hline $\begin{array}{c}\text { structure weight/ } \\
\text { passenger floor area }\end{array}$ & $\mathrm{Ib} / \mathrm{ft}^{\wedge} 2$ & 40.15 & 39.14 & 32 & 23.92 & 34.60 & 38.70 & 28.96 & 30.17 & 22.40 & 22.51 \\
\hline $\begin{array}{l}\text { fuselage weight/ } \\
\text { passenger floor area }\end{array}$ & $\mathrm{Ib} / \mathrm{ft}^{\wedge} 2$ & 14.85 & 14.68 & 11.03 & 10.31 & 10.00 & 12.21 & 9.76 & 11.10 & 13.12 & 10.05 \\
\hline
\end{tabular}

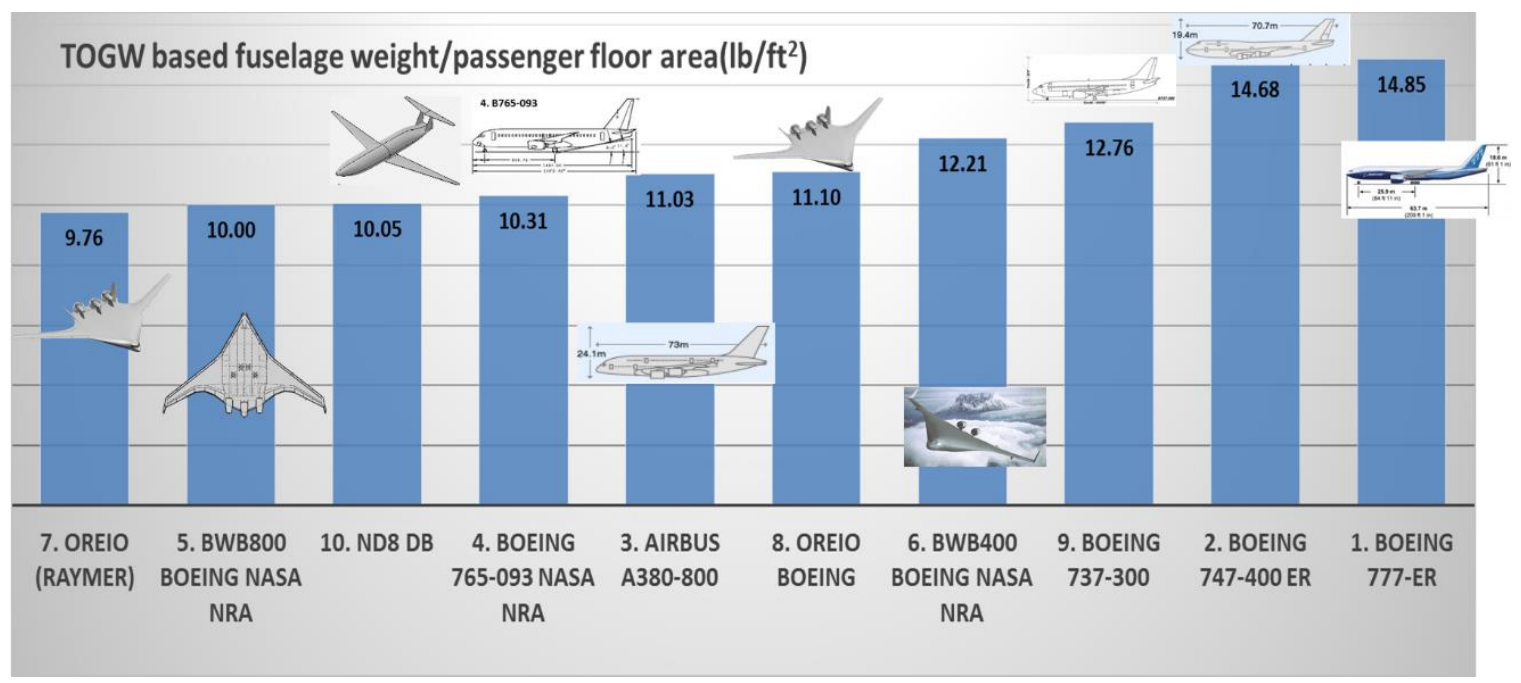

Figure 8. Bar chart of ten commercial and concept aircraft fuselage empirical weights normalized by the corresponding passenger floor area $\left(\mathrm{lb} / \mathrm{ft}^{2}\right)$ from Table 5.

A notional full vehicle model with a scaled up $125 \%$ double-D type fuselage was developed and initial structural analysis results are shown Fig. 9. The fuselage design adopts the configuration in Fig. 3(c) and Fig. 6. The fuselage height is 180 inches and the width is 315 inches. Dimensions correspond approximately to a $125 \%$ scaled up version of the original D8 fuselage which has a height of 148 inches and a width of 208 inches. The wing has a span of 2216 inches, the root chord is 330 inches, and the tip chord is 88 inches. The two main spars, upper and lower skin and ribs are made of aluminum alloy and have thickness of 0.20 inches. The wing elliptic loading is derived from the maximum takeoff gross weight of $160,000 \mathrm{lb}$ at $2.5 \mathrm{~g}$ pull up condition and a safety factor of 1.5 . The ultimate wing design load 
is applied as a normal upward pressure step load at 10 wing stations. The maximum tip deflection at this ultimate $2.5 \mathrm{~g}$ design load is 56.9 inches. The fuselage has 80 frames at 20 inch spacing, nose-cone, tail-cone, and two bulkheads. Total fuselege nose to tail length is 1862 inches. The maximum fuselage deflection with the 18.4 psi design pressure is also shown in Fig. 9. The maximum deflection is 1.9 inches at the passenger floor. The maximum deflection on the fuselage crown is 0.8 inch.

The initial total structural weight estimate is $52292 \mathrm{lbs}$. The fuselage weight including nose and tail cone is 30269 $l b s$ and the ratio of fuselage weight to the total floor area of $2869 \mathrm{ft}^{2}$ is $10.55 \mathrm{lb} / \mathrm{ft}^{2}$ with aluminum construction. This weight ratio is higher than the empirical weight ratio of the ND8 fuselage $\left(10.05 \mathrm{lb} / \mathrm{ft}^{2}\right)$ in Table 5 and Fig. 8. If only the barrel section of the fuselage is considered, the weight ratio is $12.59 \mathrm{lb} / \mathrm{ft}^{2}$. This weight ratio is lower than the ratio of fuselage FEM weight to the passenger floor area for the double-D fuselage section $\left(13.15 \mathrm{lb} / \mathrm{ft}^{2}\right)$ in Fig. 7, which may be more realistic.

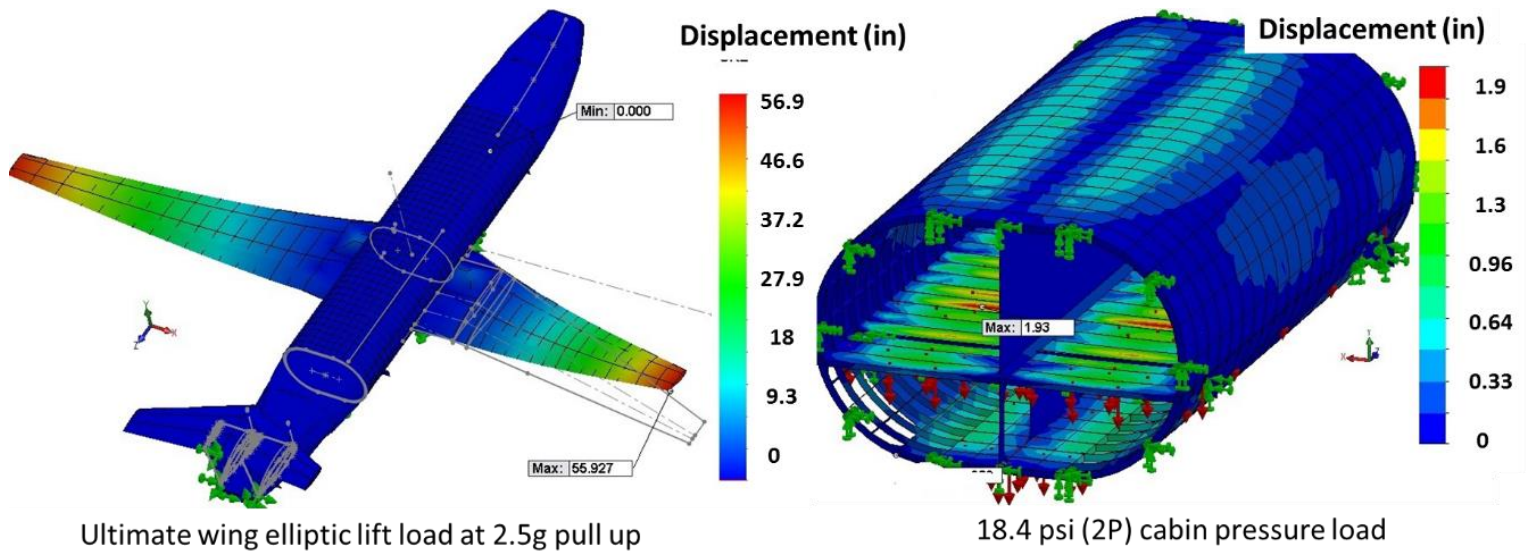

Figure 9. Structural analysis of a notional full vehicle model with a scaled up 125\% double-D type fuselage.

Table 6. Structural component weight of a notional vehicle with double-D type fuselage.

\begin{tabular}{|l|r|r|r|}
\hline Twin Barrel Fuselage weight & 22662 Ibs & \\
\hline Nose cone weight & 3372 Ibs & & \\
\hline Tail Cone weight & 4234 & & \\
\hline & & & \\
\hline
\end{tabular}

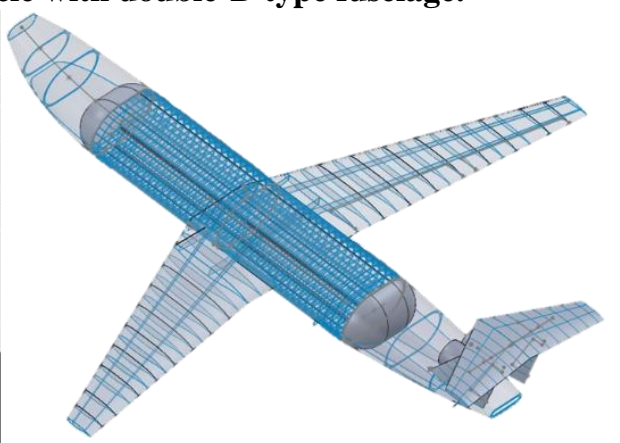

VII. Conclusions

Based on lessons learned from previous structural system design studies of unconventional transport aircraft fuselage designs, a set of finite-element models are developed and evaluated for structural design and analysis of three double-bubble concepts with advanced stitched composite construction. The structural finite element model (FEM) weights are compared with both a conventional cylindrical aluminum fuselage and a hybrid-wing-body composite fuselage. For a meaningful comparison, each structural weight is normalized by the corresponding passenger floor area, since it is a measure of the payload capacity or revenue generating capability. This ratio of structural weight to passenger floor area varies from $11.6 \mathrm{lb} / \mathrm{ft}^{2}$ for the advanced composite Hybrid-Wing-Body multibay section, to $14.73 \mathrm{lb} / \mathrm{ft}^{2}$ for the conventional cylindrical aluminum fuselage. Among the three double-bubble concepts, the double-D section fuselage structural weight is lower than the weight of other two concepts. Based on the present design configuration, the ratio of the FEM structural weight to the passenger floor area for the double-D fuselage section is $13.15 \mathrm{lb} / \mathrm{ft}^{2}$. 
Fuselage weight estimates of ten commercial and conceptual transport aircraft were also presented to complement the FEM-based weight estimation. These fuselage weight estimates were derived from the maximum takeoff gross weight and an regression-based method presented in the aircraft conceptual design text book by Raymer and from design reports. This ratio of entire fuselage structural weight to the total passenger floor area for the Boeing 777-ER aircraft is $14.85 \mathrm{lb} / \mathrm{ft}^{2}$. Both the empirical and FEM-based fuselage structural weight ratio plots show consistent trends that can be valuable for structural efficiency analysis.

A preliminary finite element model of a notional aircraft with a double-D section fuselage was also described. The fuselage FEM weight including nose and tail cone is $30269 \mathrm{lbs}$. The ratio of the fuselage FEM structural weight over the total floor area of $2869 \mathrm{ft}^{2}$ is estimated at $10.55 \mathrm{lb} / \mathrm{ft}^{2}$ with aluminum construction. This structural weight ratio is similar to that of empirical weight ratio of $10.05 \mathrm{lb}_{\mathrm{ft}} \mathrm{t}^{2}$, which is based on the maximum takeoff gross weight. If only the barrel section of the fuselage is considered, this FEM weight ratio is $12.59 \mathrm{lb} / \mathrm{ft}^{2}$. This empirical weight ratio is relatively lower than the double-D fuselage section FEM weight ratio of $13.15 \mathrm{lb} / \mathrm{ft}^{2}$ which may be more realistic. These normalized weight ratios generally complement each other, although they were estimated by two entirely different methods. The FEM analysis and the empirical structural weight tables presented in this paper provide a meaningfull comparison and confidence in the structural systems study process.

\section{Acknowledgments}

Authors thank the Advanced Air Transport Technology (AATT) Project for funding this research, AATT Project Manager Jim Heidmann, and Systems Analysis \& Integration Lead, William Haller for their guidance. Authors also acknowledge technical support from William Kimmel, Chief Technologist, Systems Analysis and Concepts Directorate, Daniel Williams, Branch Head, and Philip Arcara, Assistant Branch Head, Aeronautics Systems Analysis Branch. Thanks are also due to all the technical reviewers for improving the paper significantly. Technical discussion with Andrew Hahn, Eric Olson, and Frank Gern are greatly appreciated.

\section{References}

${ }^{1}$ Drela. M., "Development of the D8 Transport Configuration," AIAA Paper 2011-3970, 29th AIAA Applied Aerodynamics Conference, Honolulu, HI, June 2011.

${ }^{2}$ Greitzer, E. M., Bonnefoy, P. A., Rosa Blanco, E. D., Pertuze, C. S., Sato, S., Drela, M. et.al., "MIT N+3 Aircraft Concept Designs and Trade Studies, Final Report," NASA/CR 2010-216794/VOL I, 2010.

${ }^{3}$ Pitera, D. M., DeHaan, M., Brown, D., Kawai, R.T., Hollowell, S., Camacho, P., Bruns, D., and Rawden, B. K., "Blended Wing Body Concept Development with Open Rotor Engine Integration (OREIO)," NASA/CR-2011-217303/VOL II, Nov. 2011.

${ }^{4}$ Gern, F., "Conceptual Design and Structural Analysis of an Open Rotor Hybrid Wing Body Aircraft," AIAA Paper 2013-1688, 54th AIAA/ASME/ASCE/AHS/ASC Structures, Structural Dynamics, and Materials Conference, Boston, MA, April 2013.

${ }^{5}$ Przekop, A., Wu, H. T., Shaw, P., "Nonlinear Finite Element Analysis of a Composite Non-Cylindrical Pressurized Aircraft Fuselage Structure," AIAA-2014-1064, 55th AIAA/ASME/ASCE/AHS/ASC Structures, Structural Dynamics, and Materials Conference, National Harbor, MD, January 2014.

${ }^{6}$ Mukhopadhyay, V., "Hybrid-Wing-Body Vehicle Composite Fuselage Analysis and Case Study," AIAA Paper 2014-2427, AIAA AVIATION 2014 Conference, Atlanta, June 2014.

${ }^{7}$ Quinlan, J. and Frank H. Gern, F. H., "Conceptual Design and Structural Optimization of NASA Environmentally Responsible Aviation (ERA) Hybrid Wing Body Aircraft," AIAA Paper 2016-0229, 57th AIAA /ASME/ASCE/AHS/ASC Structures, Structural Dynamics and Materials Conference, San-Diego, Jan 2016.

${ }^{8}$ Mukhopadhyay, V., "Composite Structure Modeling and Analysis of Advanced Aircraft Fuselage Concepts," AIAA Paper 2015-3096, AIAA Modeling and Simulation Technology Conference, Dallas, TX, June 2015.

${ }^{9} \mathrm{Li}$, V., and Velicki, A., "Advanced PRSEUS Structural Concept Design and Optimization", 12th AIAA/ISSMO Multidisciplinary Analysis and Optimization Conference, AIAA-2008-5840, Sept. 2008, Victoria, BC, Canada.

${ }^{10}$ Velicki, A., Yovanof, N., Baraja, J., Linton, K., Li, V., Hawley, A., Thrash, P., DeCoux, S., and Pickell, R., "Damage Arresting Composites for Shaped Vehicles: Phase II Final Report," NASA/CR-2011-216880, Nov. 2011.

${ }^{11}$ Przekop, A., Jegley, D. C., Lovejoy, A. E., Rouse, M. and Wu, H. T., "Testing and Analysis of a Composite Non-Cylindrical Aircraft Fuselage Structure, Part I: Ultimate Design Loads," AIAA Paper 2016-2176, 57th AIAA/ASME/ASCE/AHS/ASC Structures, Structural Dynamics and Materials Conference, San-Diego, Jan 2016.

12 SolidWorks and SolidWorks Simulation User Manual 2011, SolidWorks Corporation, Dassault Systèmes, Concord, Massachusetts.

${ }^{13}$ Raymer, D. P., “Aircraft Design: A Conceptual Approach,” 5th Edition, AIAA Education Series Publications, 2012, pp. 575-598. 